E3S Web of Conferences 1, 08006 (2013)

DOI: $10.1051 / \mathrm{e} 3$ sconf/20130108006

(c) Owned by the authors, published by EDP Sciences, 2013

\title{
Different pathways for copper sulphate and copper nitrate antioxidation and organic acid excretion in Typha latifolia?
}

\author{
L. Lyubenova ${ }^{1}$, A. Kuhn ${ }^{2}$, A. Höltkemeier ${ }^{3}$, H. Bipuah ${ }^{4}$, E. Belford ${ }^{5}$ and P. Schröder ${ }^{6}$ \\ ${ }^{1}$ Helmholtz Zentrum München, German Research Center for Environmental Health, Research unit Microbe-Plant \\ Interactions, Ingolstädter Landstr. 1, 85764 Neuherberg, GERMANY, lyudmila.lyubenova@ helmholtz-muenchen.de \\ ${ }^{2}$ Forschungszentrum Jülich GmbH, Institute of Bio- and Geosciences (IBG-2: Plant Sciences), D-52425 Jülich, \\ GERMANY, a.kuhn@fz-juelich.de \\ ${ }^{3}$ Forschungszentrum Jülich GmbH, Institute of Bio- and Geosciences (IBG-3: Agrosphere), D-52425 Jülich, \\ GERMANY, a.hoeltkemeier@fz-juelich.de \\ ${ }^{4}$ Kwame Nkrumah University of Science and Technology, Faculty of Biosciences, Department of Theoretical and \\ Applied Biology, Kumasi, GHANA, bips097@yahoo.co.uk \\ ${ }^{5}$ Kwame Nkrumah University of Science and Technology, Faculty of Biosciences, Department of Theoretical and \\ Applied Biology, Kumasi, GHANA, ejdbelford@yahoo.co.uk \\ ${ }^{6}$ Helmholtz Zentrum München, German Research Center for Environmental Health, Research unit Microbe-Plant \\ Interactions, Ingolstädter Landstr. 1, 85764 Neuherberg, GERMANY, peter.schroeder@helmholtz-muenchen.de
}

\begin{abstract}
The major topic of the present experiment was the investigation of the antioxidative enzymes and the root exudate excretion after plant exposure to copper. The copper was added for each treatment as copper sulphate and copper nitrate in the concentrations of $10 \mu \mathrm{M}, 50 \mu \mathrm{M}$ and $100 \mu \mathrm{M}$, respectively. The plant species chosen for the study was Typha latifolia. The experiment gives insight into the plant responses to different copper supplies during the same conditions of exposure. Remarkable results were obtained during the time course about the excretion of organic acids from Typha latifolia roots during one week of copper exposure. Oxalic acid, malic acid, acetic acid and lactic acid were detected. Interestingly, not all organic acids are excreted from the roots in the first hours after copper addition.
\end{abstract}

Key words: antioxidative enzymes, copper nitrate, copper sulphate, organic acids, Typha latifolia

\section{Introduction}

Copper is an essential microelement for plants, but in elevated concentrations it inhibits different important processes for the survival of the plants. Because copper is commonly used as a fungicide and also for control of algae and vascular plants in aquatic bodies (Mohanapriya et al., 2006) this element is interesting with view to its impact on phytoremediation.

The copper uptake from the soil happens in the rhizosphere surrounding the root (Dakora and Phillips, 2002); this is also the zone where a plethora of chemical reactions and biological processes take place. Release of compounds into the rhizosphere is influencing an increased availability of several nutrient elements for uptake from the plants. Under these conditions, the exudation rates are promoted by the uptake and assimilation of mineral nutrients and elements (Dakora and Phillips, 2002). Root exudates are a complex mixture and contain root border cells, extracellular enzymes, organic acids, amino acids, simple and complex sugars, and vitamins (Marschner, 1995).

Organic acids release in root exudates seems to be linked to detoxification. Malic acid, citric acid and oxalic acid have been identified as chelators of heavy metals inside the cell, converting the metals to inactive and non-toxic forms (Ma et al., 1997, Ma et al., 1998, Barbas et al., 1999). Some plant species excrete organic acids from their roots (Prasad, 2006) and others posses over mechanisms for formation of complexes of heavy metals with organic acids as mechanism for the accumulation of heavy metals (Alonso-Castro et al., 2009).

\section{Materials and Methods}

T. latifolia plants from a commercial garden center were grown for 52 days on perlite under green house conditions. The day/night rhythm was settled at 14 hours day, 10 hours night and the humidity was $60 \%$ during the whole exposure. Nutrients were supplied by Murashige 
and Skoog medium (Murashige and Skoog, 1962). On the 53rd day the Typha plants were released from the perlite. Their roots were rinsed numerous times in distilled water and transferred into $5 \mathrm{~L}$ pots each containing $4 \mathrm{~L}$ tap water with copper nitrate respectively copper sulphate added in the predetermined concentrations. The treatments lasted seven days with three different concentrations $(10 \mu \mathrm{M}, 50 \mu \mathrm{M}$ and $100 \mu \mathrm{M})$ of copper nitrate $\left(\mathrm{CuN}_{2} \mathrm{O}_{6} \cdot 3 \mathrm{H}_{2} \mathrm{O}\right)$ and respectively copper sulphate $\left(\mathrm{Cu}_{2} \mathrm{SO}_{4} .5 \mathrm{H}_{2} \mathrm{O}\right)$. The control plants grow under the same conditions, without copper treatment. The biological replicates were four plants for each concentration.

The first exudate sampling was present on the third day after the onset of the treatment, followed by daily sampling at the same time for five days. Twelve $\mathrm{mL}$ nutrition medium were picked up from the pots, filled in Falcon tubes, shock frozen in liquid nitrogen and stored by $-20^{\circ} \mathrm{C}$ until measurements.

The organic acids were analysed using capillary electrophoresis with a salicylate electrolyte (Bazzanella et al., 1997). The capillary electrophoresis (CE) system G1600A (Agilent, Böblingen, Germany) equipped with a built-in diode-array detector proceeded according to Blossfeld et al. (2011).

Ascorbate peroxidase and monodehydroascorbate reductase were determined according to the method described by Vanacker et al. (1998). The determination of the glutathione S-transferase activity was done according to the methods described by Habig et al. (1974), Scalla and Roulet (2002) and Keen et al. (1978).

The protein contents were evaluated according to the method described by Bradford (1976) using serum albumin as a standard.

\section{Results and Discussion}

The highest oxalic acid concentration was determined after $50 \mu \mathrm{M} \mathrm{CuSO}_{4}$ treatment on the $3^{\text {rd }}$ day of exposure $(\mathrm{P}<0.05)$. Compared to $50 \mu \mathrm{M} \mathrm{CuSO}$ treatment all $\mathrm{CuNO}_{3}$ treatments lead to lower oxalic acid excretion. The same correlation was established also for malic acid. The $50 \mu \mathrm{M} \mathrm{CuSO}_{4}$ lead to the highest acetic acid concentration on the $3^{\text {rd }}$ day, but this is the lowest level detected in plants exposed to $50 \mu \mathrm{M} \mathrm{CuSO}_{4}$. During the $3^{\text {rd }}$ day of exposure $\mathrm{CuSO}_{4}$ leads to higher excretion of oxalic acid, malic acid and acetic acid in $T$. latifolia exudates compared to $\mathrm{CuNO}_{3}$.

On the $4^{\text {th }}$ day of exposure the oxalic acid concentrations in the exudates of $\mathrm{CuSO}_{4}$ treated plants were strongly reduced. Malic acid concentrations are dispersed compared with those measured on the $3^{\text {rd }}$ day. $10 \mu \mathrm{M} \mathrm{CuNO}$ lead to an increase of the excretion of malic acid whereas under the influence of $100 \mu \mathrm{M}$ $\mathrm{CuNO}_{3}$, its exudation was decreased. All treatments with $\mathrm{CuNO}_{3}$ and the concentrations of $50 \mu \mathrm{M}$ and $100 \mu \mathrm{M}$ $\mathrm{CuSO}_{4}$ resulted in significantly lower excretion patterns for lactic acid as compared with $10 \mu \mathrm{M} \mathrm{CuSO}_{4}$.

The excretion trend of Typha latifolia roots on the $4^{\text {th }}$ and on the $5^{\text {th }}$ day stayed stable and malic acid was the organic acid with the highest excretion concentration in all the treatments.

Significantly higher oxalic acid and acetic acid excretion compared to $\mathrm{CuSO}_{4}$ was observed four days after the $\mathrm{CuNO}_{3}$ treatment. The oxalic acid was significantly increased compared to the control and to the matching concentrations of the $\mathrm{CuSO}_{4}$ treatments.

On the last day of copper treatment, the acetic acid excreted from $T$. latifolia roots was significantly lower in the samples treated with $\mathrm{CuNO}_{3}$ compared to $\mathrm{CuSO}_{4}$, whereas $100 \mu \mathrm{M} \mathrm{CuSO}_{4}$ lead to the highest acetic acid concentrations determined in all exudate samples. On the $7^{\text {th }}$ day of exposure the levels of oxalic acid determined after $10 \mu \mathrm{M}$ and $100 \mu \mathrm{M} \quad \mathrm{CuSO}_{4}$ arrived the concentrations measured on the $3^{\text {rd }}$ day and the exposure to $50 \mu \mathrm{M} \mathrm{CuSO}_{4}$ led to increased exudation compared with the previous days of exposure but reached only the half of the concentration measured on the $3^{\text {rd }}$ day.

Additional to the exudate evaluation the antioxidative enzymes of Typha latifolia were also investigated. The aim was to look for additional details for the well being of the plants after the exposure to copper. Increasing copper sulphate concentrations in the roots do not lead to influence in the ascorbate cycle. In contrary to that, copper nitrate influences ascorbate peroxidase and the monodehydroascorbate reductase in the roots and lead to their increase with increasing concentrations. During the exposure, ascorbate peroxidase is induced in the leaves with increasing copper sulphate concentration, but the monodehydroascorbate reductase activity is strongly reduced in the same course. This means that the detoxification of copper sulphate and copper nitrate in the leaves and in the roots is happens different.

The glutathione S-transferases (GST) determined in Typha latifolia after copper exposure present very different pictures in the different tissues. In the roots and in the leaves GST activity was determined for the model substrates CDNB, NBC, Fluorodifen and pNpa. The highest GST activity in the roots was determined for the model substrate Fluorodifen. In the leaves the highest GST activity was determined for $\mathrm{pNpa}$ but significant differences in the leaf GST activity after copper sulphate and copper nitrate were determined for the model substrate NBC. Exposure to $\mathrm{CuSO}_{4}$ leads to significant increase with increasing concentrations, after $\mathrm{CuNO}_{3}$ exposure there is an increase in the NBC-GST-activity from $10 \mu \mathrm{M}$ to $50 \mu \mathrm{M}$ and very strong decrease after that by $100 \mu \mathrm{M} \mathrm{CuNO}_{3}$ (lower than the level of $10 \mu \mathrm{M}$ ). This leads to the conclusion that different GST isoforms are responsible for the NBC conjugation after copper sulphate and copper nitrate exposure.

\section{Conclusion}

The source of copper is decisive about the reactions of plants. Counter-ions might play a role in stress development and defense. The practical aspect of the present study is the application of Typha latifolia for phytoremediation on copper contaminated sites, which could be assisted by its high biomass and its extensive distribution in Europe. The plants possess a potent detoxification system, and some reactions might be induced while others can be heavily impaired. An additional interesting feature of further research is the 
relation between copper uptake, organic acid excretion and the role of rhizospheric microorganisms which might influence the vitality of the system.

\section{Acknowledgements}

Financial support for H.B. in the course of an IAESTE grant by the DAAD is gratefully accepted.

\section{References}

Alonso-Castro, A.J., Carranza-Álvarez, C.C., Alfredo-De la Torre, M.C., Chavez-Guerrero, L.C., Garcia-De la Cruz R.F., 2009. Removal and accumulation of cadmium and lead by Typha latifolia exposed to single and mixed metal solutions. Archives of Environmental Contamin and Toxicology 57, 688-696.

Barbas, C., Garcia, J.A.L., Manero F.J.G., 1999. Separation and identification of organic acids in root exudates of Lupinus luteus by Capillary Zone Electrophoresis. Phytochemical Analysis 10, 55-59.

Bazzanella, A., Lochmann, H., Mainka, A., Bächmann K., 1997. Determination of inoroganic anions, carboxylic acids and amino acids in plant matrices by capillary zone electrophoresis. Chromatographia $45,59-62$.

Blossfeld, S., Gansert, D., Thiele, B., Kuhn, A.J., Lösch, R., 2011. The dynamics of oxygen concentration, $\mathrm{pH}$ value, and organic acids in the rhizosphere of Juncus spp. Soil Biology and Biochemistry 43, 1186-1197.

Bradford, M.M. 1976. A rapid and sensitive method for the quantification of microgram quantities of protein utilizing the principle of protein dye-binding. Analytical Biochemistry 72, 248-254.

Dakora, F.D., Phillips, D.A., 2002. Root exudates as mediators of mineral acquisition in low-nutrient environment. Plant and Soil 245, 35-47.

Habig, W.H., Pabst, M.J., Jakoby, W.B., 1974. Glutathione S-transferases: the first enzymatic step in mercapturic acid formation. Journal of Biological Chemistry 249, 7130-7139.

Keen, J.H., and Jacoby, W.B. 1978. Glutathione transferases. Catalysis of nucleophilic reaction of glutathione. Journal of Biological Chemistry 253, 5654-5657.

Ma, J.F., Hiradate, S., Nomoto, K., Iwashita, T. Matsumoto, H., 1997. Internal detoxifycation mechanism of Al in Hydragea (Identification of Al form in the leaves). Plant Physiology 113, 1033-1039.

Ma, J.F., Hiradate, S., Matsumoto, H., 1998. High aluminium resistance in buckwheat. II. Oxalic acid detoxifies aluminium internally. Plant Physiology 117, 753-759.

Marschner, H., 1995. Mineral nutrition of higher plants. Academic Press (2nd edn), London, pp. 889.

Mohanapriya, S., Senthilkumar, P., Sivakumar, S., Dineshkumar, M., Subbhuraam, C.V., 2006. Effects of copper sulphate and copper nitrate in aquatic medium on the restoration potencial and accumulation of copper in stem cuttings of the terrestrial medicinal plant, Portulaca oleracea Linn. Environmental Monitoring and Assessment 121, 233-244.

Murashige, T., Skoog, F., 1962. A revised medium for rapid growth and bioassays with tobacco tissues cultures. Physiologia Plantarum 15, 473-497.

Prasad, M.N.V., 2006. Metallothioneins, metal binding complexes and metal sequestretaion in plants. In: Heavy metal stress in plants. From Biomoleculs to ecosystems. MNV Prasad (eds), Springer Berlin Heidelberg, pp. 47-83.

Scalla, R., and Roulet, A. 2002. Cloning and characterization of a glutathione S-transferase induce by a herbicide safener in barley (hordeum vulgare L.). Physiologia Plantarum 116, 336-344.

Vanacker, H., Carver, T.L.W., Foyer, C.H. 1998. Phatogen induced changes in the antioxidant status of the appoplast in barley leaves. Plant Physiology 117, 1103-1114. 